\title{
Relato de Terapeutas sobre o Impacto da Autorrevelação
}

\section{Therapist's Report about the Self-disclosure Impact \\ Informe del Terapeuta sobre el Impacto la Auto-revelación}

\author{
Fernanda Ban Greboggy ${ }^{1}$, Jocelaine Martins da Silveira ${ }^{2}$
} [1,2] Universidade Federal do Paraná I Título abreviado: Relato de Terapeutas sobre o Impacto da Autorrevelação | Endereço para correspondência: Rua
Comendador Macedo, 159, apto. 2 - Curitiba, Paraná - 80060-030 | Email: fernandabgreboggy@hotmail.com | DOI: 10.18761/pac.2016.018

\begin{abstract}
Resumo: O presente projeto se propôs a investigar o uso da autorrevelação por terapeutas estudantes de psicologia, em treino em uma universidade pública paranaense, e como esse uso é experienciado. $\mathrm{O}$ método utilizado consistiu em aplicar questionários a $(\mathrm{N}=11)$ terapeutas em treino solicitando-os a relatar o uso da autorrevelação e o impacto dela na interação terapêutica. Criou-se, para isto, um questionário que foi entregue a cada participante uma vez por semana, durante seis semanas. Os dados coletados foram analisados pela categorização e verificação de possíveis relações entre o uso de autorrevelações e categorias relacionadas ao nível de conforto do terapeuta participante. Os resultados indicam que em 47,6\% dos protocolos preenchidos, o terapeuta relatou o uso de uma autorrevelação, e que este uso se deu visando a melhora do cliente e fortalecimento da relação terapêutica. Também foi observada uma porcentagem de $81,25 \%$ de relatos de satisfação em relação às autorrevelações. Foi observado ainda o relato de fortalecimento na relação terapêutica relacionado ao uso de autorrevelações. Discutiu-se que o uso de autorrevelações pelos terapeutas participantes deste estudo tem suporte da literatura, assim como a relação entre o modo como o terapeuta o experiencia e sua percepção sobre o impacto no cliente.
\end{abstract}

Palavras-chave: autorrevelação, psicoterapia analítico-funcional, terapia analítico-comportamental. 
Abstract: The present study proposed to investigate about the use of self-disclosure by psychology graduates therapists, being trained at a state university in Paraná, and how they experience this use. The method used was composed by administer a questionnaire to $(\mathrm{N}=11)$ training therapists, requesting them to relate if they had a self-disclosure and the effect in therapist-client interaction. To do it, a questionnaire has been created and handed to each participant once a week, for six weeks. The collected data has been categorized and the possible relations between the self-disclosure's use and categories related to the therapists participants comfort level has been tested. So, at $47,6 \%$ of the filled protocols, the therapist related a selfdisclosure and that was used aiming patient and relationship's benefits. Also, a $81,25 \%$ percentage of satisfaction reports was notice about the self-disclosure. Furthermore, the report of strengthen in therapist-client relationship related with the self-disclosures were also noticed. It has been discussed that the use of self-disclosure by the study participants therapists has a base in literature, as well as the relation between the way the therapist experiences and his perception of the effect on client.

Keywords: self-disclosure, functional analytic psychotherapy, behavior analytic therapy.

Resumen: Este proyecto tiene como objetivo investigar el uso de auto-revelación por terapeutas estudiantes de psicología en graduación, en una universidad pública en Paraná, y como vivenciam este uso. El método utilizado fue aplicar cuestionarios $(n=11)$ a terapeutas en formación, que pedía el reporte del uso de auto-revelación y su impacto en la interacción terapéutica. Fue creado para esto un cuestionario que fue dado a cada participante una vez a la semana durante seis semanas. Los datos recogidos se analizaron por clasificación y verificación de posibles relaciones entre el uso de autorrevelações y categorías relacionadas con el nivel de comodidad del terapeuta participante. Los resultados indican que en 47,6\% de protocolos terminados, el terapeuta informó hacer un auto-revelación, y que se hizo uso pretendendo la mejora del cliente y fortificación de la relación terapéutica. También se observó un porcentaje de $81,25 \%$ de informes de satisfacción en relación a las auto-revelaciones. Se observó también el informe de fortalecimiento de la relación terapéutica relacionado con el uso de auto-revelaciones. Se ha argumentado que el uso de auto-revelaciones por los terapeutas participantes en este estudio tiene soporte en literatura, así como la relación entre la forma en que el terapeuta lo experiencia y su percepción del impacto en el cliente.

Palabras-clave: auto-revelación, psicoterapia analítico funcional, terapia analítica-conductual. 
A FAP é uma psicoterapia baseada na análise do comportamento e utiliza reforço natural durante a sessão para modificar o comportamento do cliente, pois "tudo que um terapeuta pode fazer para auxiliar os clientes ocorre durante a sessão" (Kohlenberg \& Tsai, 1991, p.19; Wielenska \& Oshiro, 2012). Kohlenberg e Tsai (1991) organizam os Comportamentos Clinicamente Relevantes (CRBs), que são foco de atenção do terapeuta, em três categorias. A primeira é o CRB1, que se refere aos problemas do cliente que ocorrem durante a sessão e que devem ter a frequência diminuída ao longo da terapia. A segunda é o CRB2, referente aos progressos do cliente que ocorrem durante a sessão e que devem ser fortalecidos ao longo da terapia. E o terceiro o CRB3, que se refere às interpretações do cliente sobre o próprio comportamento, o que pode ajudar o cliente a obter acesso a reforçadores no contexto fora da sessão.

Kohlenberg e Tsai (1991) também propõem cinco regras para o terapeuta na aplicação da FAP. A Regra 1 é prestar atenção aos CRBs, pois sendo a consequenciação por parte do terapeuta o principal norteador para o comportamento do cliente no contexto da terapia, o não reconhecimento dos CRBs poderia resultar em consequenciações inapropriadas, o que poderia reforçar um comportamento inadequado do cliente e/ou deixar de reforçar um comportamento adequado. A Regra 2 é evocar CRBs, pois, na opinião dos autores, "um relacionamento terapeuta-cliente ideal evoca CRB1 e cria condições para o desenvolvimento de CRB2" (Kohlenberg \& Tsai, 1991). A Regra 3 é reforçar CRB2s para que estes comportamentos aumentem de frequência. A Regra 4 é observar os efeitos potencialmente reforçadores que o comportamento do terapeuta possa ter em relação aos CRBs do cliente e assim possibilitar que o terapeuta tenha consciência dos reais efeitos que seu comportamento tem no cliente. Por fim, a Regra 5 é fornecer interpretações ao cliente das variáveis que afetam seu comportamento e assim facilitar sua compreensão das interações que ele tem com o ambiente e de como ele pode muda-las (Kohlenberg \& Tsai, 1991).

Segundo Weeks, Kanter, Bonow, Landes \& Busch (2011), para a aplicação das cinco regras da FAP é necessário que já tenha sido estabelecida uma relação psicoterapêutica sólida e que o cliente tenha consentido com o trabalho focado na relação. Também é recomendado que os CRBs sejam definidos conjuntamente com o cliente e que o terapeuta crie um contexto de segurança e confiança na relação. Os autores afirmam que terapeutas FAP são encorajados a utilizar reforçadores naturais nas sessões como expressões de cuidado, dizer ao cliente como se sente sobre ele no momento ou expressar uma conexão interpessoal de forma não verbal, e Kohlenberg e Tsai (1991); Knott, Wetterneck, Derr e Tolentino (2015); Tsai, Kohlenberg, Kanter, Kohlenberg, Follette, e Callaghan (2011b) ainda indicam a FAP como uma terapia que trata as dificuldades interpessoais do cliente por meio da relação terapêutica. Weeks et al (2011) justificam que o responder do terapeuta em uma relação terapêutica intensa desenvolve de forma eficaz o repertório interpessoal do cliente, o que é generalizado para as suas interações fora da terapia. $\mathrm{O}$ uso de emoções e foco na relação terapêutica não é, porém, exclusivo da FAP, outras abordagens também fazem este uso, como a terapia focada na emoção (tradução livre da autora), que é uma intervenção integradora-humanista (Timulak, 2014). O presente estudo, entretanto, será focado na FAP.

Porém, segundo Braga e Vandenbergue (2006), a terapia comportamental, em seu surgimento, dava pouca importância à relação entre cliente e terapeuta e foi apenas a partir da década de 70 que fatores mais ligados a essa relação, como aceitação e autorrevelação mútua que passaram a ganhar atenção. Em relação à FAP, por exemplo, Weeks et al (2011) afirmam que a observação do terapeuta sobre qual o impacto dos comportamentos do cliente sobre o próprio terapeuta é importante para identificar potenciais CRBs e antecipar o impacto desses sobre outras pessoas que têm contato com o cliente.

Além disso, em um estudo sobre a conceitualização da intimidade por terapeutas analítico-comportamentais, um dos resultados obtidos por Silveira e Guenzen (2013) foi que os terapeutas concordaram que a intimidade tem influência positiva nos resultados do tratamento e na relação terapêutica. Além disso, em um estudo sobre o impacto da autorrevelação, Guenzen (2014) observa que houve diminuição no escore de depressão do cliente na Escala de Depressão de Beck (BDI) ao longo das sessões em que foram realizadas autor- 
revelações do terapeuta. E que os escores do inventário de habilidades sociais passaram de abaixo da média para acima da média. Adicionalmente, Knott, Wetterneck, Derr e Tolentino (2015) citam a autorrevelação como parte de uma interação genuína e que promove reforçamento natural.

Ainda no estudo de Guenzen (2014), boa parte dos turns categorizados como CRBs e Os se deu imediatamente após a autorrevelação do terapeuta. Assim, das 36 autorrevelações do terapeuta 19 foram seguidas por CRB2 e 4 por O2 - discussão de melhorias fora da relação terapêutica (Callaghan e Follette, 2008) - enquanto 6 foram seguidas por CRB1 e apenas 1 por $\mathrm{O} 1$ - discussão de problemas fora da relação terapêutica (Callaghan e Follette, 2008) - sendo as outras 6 colocadas na categoria outros códigos. Estes resultados indicam então que nessa pesquisa a autorrevelação teve um papel importante de evocação de comportamentos que caracterizam uma melhora do cliente. Muitas das verbalizações do cliente que seguiram a autorrevelação foram autorrevelações também, o que exige uma relação terapêutica bem estabelecida.

É interessante como, mesmo com duas décadas entre as publicações, esses resultados estão de acordo com a observação de Banaco (1993) de que trabalhos sobre as habilidades pessoais do terapeuta têm enfoque nos aspectos que visam assegurar o bem-estar do cliente. Porém, o autor fala das dificuldades experienciadas por terapeutas iniciantes e, ao citar a frequente exigência de que o terapeuta não tenha sentimentos, o autor ressalva que "ele [o terapeuta] também é uma pessoa que tem sua história de reforçamento e (...) devemos também levar em conta seus sentimentos e pensamentos" (Banaco, 1993, p.75).

Retomando estudos mais recentes, Manduchi e Shoendorff (2012) ainda definem a FAP como "uma terapia que promove intensas e curativas relações terapêuticas e convida o terapeuta a usar sua própria experiência privada no-momento para fomentar estas relações" (Manduchi \& Shoendorff, 2012 , p. 72) e lembram que este convite pode ser desafiador para o terapeuta que está considerando usar a FAP. Também é interessante considerar que este convite não é o único elemento relacionado à FAP que pode ser considerado desafiador, já que a palavra "coragem" está no próprio subtítulo do livro organizado por Tsai et al. (2011b). Além disso, Knott, Wetterneck, Derr e Tolentino (2015) ainda apontam a FAP como uma terapia que promove comportamentos de intimidade tanto do terapeuta quanto do cliente.

Existem ainda estudos que versam sobre a influência mútua entre cliente e terapeuta. Por exemplo, o estudo de Silva (2012) que, ao analisar os efeitos da metáfora no processo de terapia analítico comportamental, observou que o material utilizado para estimulação suplementar também teve efeito no comportamento do terapeuta, que usou mais metáforas com o seu uso, e que "quanto mais um dos membros da díade emitiu metáforas, mais o outro as emitiu em resposta" (Silva, 2012, p.60). O material consistia em imagens, das quais a cliente deveria escolher quais representavam partes importantes em sua vida. Esses dados trazem indícios importantes da condição de pessoa do terapeuta dentro dessa interação.

Outro estudo que perpassa o tema é o de Silveira e Guenzen (2013) que ao questionar terapeutas sobre o impacto emocional que uma relação terapêutica de intimidade tem sobre o terapeuta, mais da metade (52\%) considerou que a interação resultou em satisfação, 15\% respondeu que depende do tipo de interação, 11\% respondeu que os resultados são nulos, $8 \%$ consideraram que resultou em mais preocupação e cuidado com o cliente e apenas $3 \%$ relatou que resultou em adversidade. E que grande parte dos terapeutas comportamentais considerou a intimidade na relação terapêutica como um processo bidirecional, ou seja, um processo em que o terapeuta também está incluído. Outro dado interessante se considerarmos o terapeuta como pessoa é que, ao serem questionados sobre ações realizadas na clínica que caracterizavam intimidade com o cliente, mais da metade dos terapeutas deu respostas evasivas ou deixou de responder, o que, ainda segundo Silveira e Guenzen (2013), poderia ter como uma das explicações a recomendação de cautela no uso de intimidade dada por alguns autores, o que deixaria os terapeutas pouco confortáveis em dar exemplos sobre o tema.

Adicionalmente, boa parte dos estudos que discutiam sobre esse tema era sobre a supervisão. Em seu estudo, Guenzen (2014) atentou inclusive 
para a importância da supervisão na minimização dos riscos da autorrevelação e na identificação por parte da terapeuta das variáveis que interferiam em seu comportamento e no processo terapêutico.

No caso descrito por Manduchi e Shoendorff (2012), por exemplo, foi relatado que os comportamentos da cliente na terapia geraram na terapeuta um forte sentimento de incompetência e desejo de se afastar da cliente quando ela emitia esses comportamentos. Assim como teve dificuldade em se conectar com o supervisor e necessitou da ajuda do supervisor para se sentir cuidada e expressar seus sentimentos em relação à supervisão e às sessões.

Manduchi e Shoendorff (2012) ainda afirmam que alguns comportamentos da cliente faziam com que ambas (cliente e terapeuta) se sentissem mais afastadas uma da outra, e que a expressão deste sentimento pela terapeuta tinha um papel importante na terapia. Relataram também que foi desafiador para a terapeuta que sentia medo de não conseguir ajudar e de não ser boa o bastante. Assim, esse estudo traz um bom exemplo da condição do terapeuta como pessoa.

Outro estudo que aborda o tema de supervisão é o de Kameyama (2012), que acompanhou três evoluções de casos clínicos nos quais foram feitas intervenções sobre comportamentos dos clientes que produziam sentimentos negativos no terapeuta, e as supervisões dos mesmos. Nessas, as terapeutas relatavam esses sentimentos, desconfortos e inseguranças e assim podiam refletir melhor junto com a supervisora sobre como usá-los na terapia. Um exemplo é o das dificuldades de uma das terapeutas, que ainda estava em formação, em lidar com os comportamentos de Demanda Indevida - demandas apresentadas pelo cliente que causam desconforto no terapeuta (Kameyama, 2012) - frequentemente emitidos por sua cliente. Os casos descritos em tais estudos evidenciam o papel de pessoa do terapeuta, ponto importante para o presente estudo, que investiga como o próprio terapeuta experiencia o uso da autorrevelação.

Dentro dessa perspectiva, Tsai, Callaghan, Kohlenberg, Follette, e Darrow (2011a), afirmam que "a supervisão em FAP enfatiza o desenvolvimento pessoal do terapeuta" (Tsai et al, 2011a, p. 212). Assim, segundo os autores, um dos objeti- vos dessa supervisão é aumentar o "conhecimento emocional" do terapeuta, o que é aprendido através de uma relação interpessoal intensa com o supervisor. Os autores justificam então essa relação ressaltando o aspecto pessoal do terapeuta:

"imagine clientes cujas dificuldades são evocadas no contexto de suas relações interpessoais próximas. De forma geral, isso pode ser entendido como problema de intimidade e tende a ocorrer (em maior ou menor grau) com quase todos os clientes, assim como conosco, enquanto terapeutas ou supervisores, é muito difícil conduzir a FAP se o terapeuta tem problemas de intimidade semelhantes aos de seus clientes, e esse dilema piora se eles têm pouca percepção de como suas limitações interpessoais emergem em seu papel como terapeutas." (Tsai et al, 2011a, p. 213).

Ampliando ainda a visão do terapeuta como pessoa, Tsai, Yard e Kohlenberg (2014) citam os terapeutas FAP como terapeutas que vêem tanto os clientes como a si mesmos como pessoas que têm sua própria e complexa história de vida. Tsai et al (2011a) também indicam que uma boa FAP ocorre quando os supervisionandos a aplicam também como seres humanos, em seus relacionamentos cotidianos e não só como terapeutas. Porém alertam que é difícil estar aberto, presente e não se esquivar emocionalmente e relatam o caso de uma terapeuta em supervisão que disse não estar fazendo FAP, pois esta a obrigaria a ser mais transparente, aberta e menos protegida, e depois cita a sua relação com o supervisor e diz se sentir insegura a respeito de conseguir sustentar essa relação (Tsai et al, 2011a).

Ainda considerando questões pessoais do terapeuta, mas de forma mais voltada para as implicações dessas questões na clínica, os resultados do estudo de Wielenska e Oshiro (2012) sugerem que a FAP pode ser uma experiência significativa para o crescimento pessoal e profissional dos terapeutas. E assim, a supervisão em grupo da FAP tem o objetivo de ensinar aos supervisionandos tanto habilidades terapêuticas essenciais, quanto a estar sensível às contingencias interpessoais, e assim responder de forma a promover melhoras do cliente. 
Para isso, segundo Wielenska e Oshiro (2012), os supervisionandos se expõem e desenvolvem uma relação intensa com o supervisor, assim como emitem respostas emocionais importantes. Além disso, o supervisor pode evocar comportamentos problema do supervisionando para modela-los durante a supervisão FAP.

Um exemplo dado pelas autoras foi de um caso de supervisão em que duas supervisionandas (que atendiam o mesmo cliente) estavam evitando falar sobre as sessões e, ao confronta-las, elas assumem que estavam com medo da reação do supervisor porque elas não estavam impedindo os comportamentos do cliente que tinham função de evitar intimidade, porque elas não queriam que ele perguntasse sobre a vida delas, algo que ele fazia quando se sentia próximo delas. Além disso, uma delas disse que se sentia uma péssima terapeuta e a outra que tinha percebido que se irritou com o paciente, pois esse não teria o direito de invadir a privacidade dela. Então é relatado por Wielenska e Oshiro (2012) que o supervisor as acolheu e as instruiu a usar esses sentimentos como pistas sobre as contingências da sessão.

Ainda no mesmo artigo de Wielenska e Oshiro (2012), as autoras dão um exemplo sobre os sentimentos do terapeuta na terapia em que durante um role-playing os terapeutas "praticamente congelaram" diante da causa da depressão da "cliente" e os supervisores então discutiram paralelos entre essa reação dos terapeutas e a reação da "cliente" frente a esta situação. Após o mesmo role-playing os terapeutas foram questionados sobre como se sentiram e relataram que foi importante o entendimento da FAP, mas também foi difícil e doloroso, e que no começo lhes causou uma sensação de desamparo. De maneira semelhante, no estudo de Oliveira e Vandenberghe (2009), os terapeutas participantes relataram sentimentos como raiva, insegurança, desconforto, culpa, desesperança, etc, em relação a más experiências em sessão.

Assim, se por um lado se defende que o terapeuta aja também enquanto ser humano, estabeleça uma relação interpessoal intensa com o cliente, utilize seus sentimentos e faça autorrevelações durante as sessões como forma de fortalecer essa relação e evocar e consequenciar CRBs. E por outro são reconhecidas as dificuldades encontradas pelos terapeutas, sobretudo iniciantes, na condução da relação terapêutica em razão de fatores pessoais. Surge a questão sobre a escassez de estudos que investiguem como se dá a expressão de aspectos pessoais do terapeuta na sessão, e quais são os impactos dela para o terapeuta, e para o cliente e a interação terapêutica, de acordo com a percepção do terapeuta.

Portanto, o presente estudo teve o objetivo de investigar o uso da autorrevelação por alunos/terapeutas em formação e como este uso é experienciado por eles, e também as possíveis influências deste uso sobre o cliente, sobre a relação terapêutica e no desenvolvimento do caso clínico, sob a perspectiva do terapeuta.

\section{Método}

\section{Participantes}

A pesquisa foi realizada com 11 alunos do $10^{\circ}$ período do curso de Psicologia de uma universidade pública no sul do Brasil, matriculados em uma disciplina obrigatória da grade curricular. A ementa da disciplina prevê o treinamento de práticas psicoterápicas analítico-comportamentais.

Os participantes já haviam passado por uma disciplina anterior, que também prevê o treinamento destas práticas e todos já haviam realizado atendimentos anteriores à pesquisa. As pesquisadoras não tiveram contato com os clientes.

\section{Local}

Sala de supervisão da universidade na qual os alunos cursam Psicologia.

\section{Material}

11 envelopes pardos contendo os Protocolos de Registro de Autorrevelação do Terapeuta.

\section{Instrumento}

Protocolo de Registro de Autorrevelação do Terapeuta: foi elaborado para este estudo, levando em conta hipóteses levantadas a partir da literatura e possíveis variáveis ligadas a essas hipóteses, como o nível de conforto do terapeuta, o impacto no cliente, etc. A mesma folha foi dividida em duas 
partes, o protocolo a ser preenchido logo após o atendimento e um espaço dedicado ao Follow up.

Essa primeira parte compreende quatro questões de caracterização da sessão e do caso e 16 questões sobre o uso de autorrevelação na sessão. E a segunda parte, destinada ao Follow up, compreende 13 questões referentes a prováveis influências da autorrevelação durante as duas semanas seguintes.

\section{Aspectos éticos}

O presente estudo foi aprovado pelo Comitê de Ética em pesquisa com seres humanos em parecer consubstanciado sob o número 1343189. Os participantes leram e assinaram o termo de consentimentos livre e esclarecido.

\section{Delineamento da pesquisa}

A coleta dos dados das duas partes do protocolo foi inicialmente planejada para ser conduzida em um intervalo de seis semanas, considerando uma aferição por semana. Assim, haveria quatro aferições da primeira parte do protocolo e quatro do Follow up como ilustrado na Tabela 1:

Porém, alguns eventos como faltas e desistências dos clientes, assim como faltas dos participantes, fizeram com que o período de coleta de dados aumentasse. Desta forma, a coleta de dados ocorreu dentro de um período de 15 semanas, sendo que o intervalo de respostas de cada participante variou de 2 a 9 semanas, considerando que alguns não preencheram todos os protocolos.

Tabela 1

Planejamento para a Coleta de Dados

\begin{tabular}{|c|c|c|c|c|c|}
\hline $1^{\text {a }}$ Semana & $2^{\text {a }}$ Semana & $3^{\mathrm{a}}$ Semana & $4^{\text {a }}$ Semana & $5^{\text {a }}$ Semana & $6^{\mathrm{a}}$ Semana \\
\hline \multirow[t]{2}{*}{$\begin{array}{l}\text { Aferição da primeira } \\
\text { parte do protocolo }\end{array}$} & $\begin{array}{l}\text { Aferição da primeira } \\
\text { parte do protocolo }\end{array}$ & $\begin{array}{l}\text { Aferição da primeira } \\
\text { parte do protocolo }\end{array}$ & $\begin{array}{l}\text { Aferição da } \\
\text { primeira parte do } \\
\text { protocolo }\end{array}$ & & \\
\hline & & $\begin{array}{l}\text { Aferição do Follow } \\
\text { up da } 1^{a} \text { semana }\end{array}$ & $\begin{array}{l}\text { Aferição do Follow } \\
\text { up da } 2^{a} \text { semana }\end{array}$ & $\begin{array}{l}\text { Aferição do } \\
\text { Follow up da } 3^{a} \\
\text { semana }\end{array}$ & $\begin{array}{l}\text { Aferição do } \\
\text { Follow up da } 4^{a} \\
\text { semana }\end{array}$ \\
\hline
\end{tabular}

\section{Procedimentos}

Para o recrutamento dos participantes foi solicitado que as duas supervisoras de orientação analítico-comportamental da disciplina estendessem o convite de participação da pesquisa aos seus alunos/ terapeutas em formação.

A cada semana, durante as quatro primeiras semanas, foi entregue a cada terapeuta participante um Protocolo de Registro de Autorrevelação do Terapeuta e solicitado que a primeira parte desse fosse preenchida após uma sessão de terapia, e a partir da terceira semana, foi re-entregue também o protocolo já preenchido duas semanas antes e solicitado que fosse preenchida a segunda parte, referente ao Follow up. Para assegurar o sigilo sobre o aluno/terapeuta em formação e o cliente foi solicitado o uso de nomes fictícios e foram usados envelopes aos quais as supervisoras não tiveram acesso. As supervisões também não foram realizadas visando a orientação do uso da autorrevelação durante a coleta de dados.

\section{Análise de dados}

As respostas dadas no protocolo foram categorizadas e analisadas de modo a relacionar o efeito relatado no cliente e a influência no terapeuta, na relação terapêutica e no progresso da terapia. A categorização foi feita em grande parte pela leitura das respostas dadas, e, a partir dessas foram criadas categorias amplas, que facilitassem uma visão gráfica do conteúdo das respostas, mas que não se distanciassem das respostas originais.

Em algumas questões, foram criadas primeiramente categorias mais descritivas, que posteriormente foram agrupadas em categorias mais amplas, 
ilustradas na Tabela 2. Além disso, a categorização das breves conceituações de caso exigiram uma maior interpretação das respostas e um maior embasamento teórico em relação às outras questões.

\section{Resultados e discussão}

Os protocolos foram entregues a 11 participantes sendo que 10 retornaram algum protocolo. Ao todo, 34 protocolos preenchidos foram devolvidos. De acordo com as respostas à questão 5 "Você fez alguma autorrevelação com o cliente nesta sessão?", dos 34 protocolos preenchidos, em 16 foram registradas autorrevelações.

Dos 10 terapeutas participantes que entregaram algum protocolo, oito fizeram alguma autorrevelação (Questão 5), sendo que desses nenhum fez autorrevelações em todas as quatro sessões registradas no protocolo, três fizeram autorrevelações em três sessões, dois fizeram em duas, três fizeram em uma.

Questão 4 " Breve conceituação do caso:" - Em relação às conceituações de caso, estas foram categorizadas em dois grupos: as que o cliente "Poderia se beneficiar mais com a autorrevelação", e que "Poderia se beneficiar menos com a autorrevelação". Dos dez casos, seis estavam na primeira categoria.

Questão 8 "Descreva-a(s)" [as autorrevelações] - Dos oito terapeutas participantes que fizeram autorrevelações, três fizeram tanto "autorrevelações sobre a relação terapêutica" quanto "autorrevelações sobre experiências similares às do cliente". No total, das 16 autorrevelações feitas, sete foram sobre a relação terapêutica e nove sobre experiências similares às do cliente.

Questões 9 "Sob controle de quê você estava ao fazê-la?" e 10 "Descreva:"- Na questão sobre sob controle de quê o terapeuta estava ao fazer a autorrevelação, que era de múltipla escolha e a última opção (outros) pedia uma descrição (questão 10), alguns marcaram apenas uma opção e outros marcaram duas. Assim, dos 15 protocolos onde esta questão foi preenchida, a $1^{\text {a }}$ opção, que era “De promover autoconhecimento no cliente", foi assinalada sete vezes, a $2^{\text {a }}$ opção, "De fornecer modelo ao cliente", foi assinalada quatro vezes. A $3^{\mathrm{a}}$ opção "Da intensidade dos meus sentimentos e emoções no momento" também foi marcada quatro vezes, $\mathrm{e}$ também duas delas em conjunto com a $1^{\text {a }}$ opção.
A $4^{\text {a }}$ opção "Não estava consciente no momento", não foi assinalada. Quanto à $5^{a}$ opção "Outros", foi assinalada quatro vezes e, dessas, três descrições foram categorizadas como "Promoção de vínculo terapêutico" e um como "Outros".

Questão 11 [Como você se sentiu após fazê-la(s)?] "Durante a sessão" - Sobre como o participante se sentiu durante a sessão após fazer a autorrevelação, dos 16 preenchimentos, cinco foram categorizados como "Sentiu-se bem em fazer a autorrevelação", sete como "Sentiu algum desconforto em fazer a autorrevelação", três como "Teve sentimentos ambíguos" e um como "Outros".

Questão 12 [Como você se sentiu após fazê-la(s)?] "Após a sessão" - E, sobre como o terapeuta participante se sentiu após a sessão, dos 16 preenchimentos, 13 foram categorizados como "Sentiu-se bem em fazer a autorrevelação" e as categorias "Sentiu algum desconforto em fazer a autorrevelação", "Teve sentimentos ambíguos" e "Outros" tiveram apenas uma resposta, cada um, categorizadas como tal.

Questão 15 "Qual foi o impacto no cliente?” Sobre o impacto da autorrevelação que o terapeuta participante notou no cliente, dez das respostas foram categorizadas como "O cliente reagiu bem e foi relevante para o processo terapêutico", quatro como "O cliente reagiu bem, mas foi pouco relevante para o processo terapêutico", um como "Causou desconforto, mas foi relevante para o processo terapêutico" e um como "Causou desconforto e foi pouco relevante para o processo terapêutico", considerando o progresso da sessão.

Questão 16 "Como você se sentiu com impacto da autorrevelação no cliente?” - Na questão sobre como o participante se sentiu com o impacto da autorrevelação no cliente, 14 respostas foram categorizadas como "Sentiu-se bem", um como "Sentiu algum desconforto", e um como "Outros".

As respostas das demais questões estão descritas nas Tabelas 2 e 3.

Em relação ao uso da autorrevelação pelos participantes do estudo, foi relatado o uso de autorrevelações em $47,06 \%$ dos protocolos preenchidos, o que é um dado potencialmente positivo, uma vez que, segundo Tsai, Yard e Kohlenberg (2014), as autorrevelações podem melhorar a relação terapêutica, demonstrar sinceridade e desenvolver o comportamento de intimidade, por exemplo. 


\section{Tabela 2}

\section{Descrição de respostas a questões referentes à primeira parte do protocolo}

\begin{tabular}{|c|c|c|}
\hline Questão & Não & Sim (categorias) \\
\hline $\begin{array}{l}\text { (5) Você fez alguma autorrevelação com o cliente } \\
\text { nesta sessão? }\end{array}$ & 18 & $\begin{array}{l}7 \text { - "autorrevelações sobre a relação terapêutica" } \\
9 \text { - "autorrevelações sobre experiências similares } \\
\text { às do cliente" }\end{array}$ \\
\hline $\begin{array}{l}\text { (6) Havia autorrevelações planejadas para a ses- } \\
\text { são? }\end{array}$ & 17 & $\begin{array}{l}1 \text { - "O cliente trouxe a demanda de falar sobre } \\
\text { outro assunto na sessão" }\end{array}$ \\
\hline $\begin{array}{l}\text { (13) Em sessões subsequentes com esse cliente, } \\
\text { você gostaria de repetir a autorrevelação? }\end{array}$ & 5 & $\begin{array}{l}8 \text { - "Faria autorrevelações semelhantes" } \\
1 \text { - "Faria outros tipos de autorrevelações" } \\
2 \text { - "Não descreveu o tipo de autorrevelação" }\end{array}$ \\
\hline $\begin{array}{l}\text { (17) Houve alguma influência da autorrevelação na } \\
\text { relação terapêutica? }\end{array}$ & 6 & 10 - "A relação terapêutica foi fortalecida" \\
\hline $\begin{array}{l}\text { (19) Você considera que esta autorrevelação valeu } \\
\text { a pena? }\end{array}$ & 3 & 13 \\
\hline $\begin{array}{l}\text { (20) Você está à vontade para relatá-la para o seu } \\
\text { supervisor? }\end{array}$ & - & 16 \\
\hline
\end{tabular}

\section{Tabela 3}

Descrição das respostas às questões referentes ao Follow Up

\begin{tabular}{|c|c|c|}
\hline Questão & Não & Sim (categorias) \\
\hline $\begin{array}{l}\text { (22) Você sentiu algum impacto em seu comporta- } \\
\text { mento ao longo destas duas semanas que pudesse } \\
\text { estar relacionado à sua autorrevelação? }\end{array}$ & 10 & $\begin{array}{l}2 \text { - "Notou que o próprio comportamento ficou mais } \\
\text { confiante" } \\
1 \text { - "Notou que ficou mais alerta às próprias autor- } \\
\text { revelações" } \\
4 \text { - "Citou uma melhora na relação terapêutica ou } \\
\text { no cliente" }\end{array}$ \\
\hline $\begin{array}{l}\text { (24) Houve impacto no comportamento do cliente ao } \\
\text { longo destas duas semanas? }\end{array}$ & 6 & $\begin{array}{l}8 \text { - "O paciente passou a ser mais aberto na rela- } \\
\text { ção terapêutica" } \\
1 \text { - "O paciente apresentou melhoras fora do con- } \\
\text { texto terapêutico" } \\
1 \text { - "Outros" } \\
1 \text { - não foi preenchido }\end{array}$ \\
\hline $\begin{array}{l}\text { (26) Houve impacto na relação terapêutica ao longo } \\
\text { destas duas semanas? }\end{array}$ & 9 & $\begin{array}{l}6 \text { - "A relação terapêutica ficou mais forte" } \\
1 \text { - "Outros" } \\
1 \text { - não foi preenchido }\end{array}$ \\
\hline $\begin{array}{l}\text { (28) Houve algum impacto positivo no progresso do } \\
\text { tratamento após estas duas semanas? }\end{array}$ & 7 & $\begin{array}{l}8 \text { - "Progressos no tratamento por parte do cliente" } \\
2 \text { - "Progressos na relação terapêutica". }\end{array}$ \\
\hline $\begin{array}{l}\text { (30) Você mudou de ideia (nestas duas semanas) } \\
\text { quanto à fazer ou não a autorrevelação novamente? }\end{array}$ & 17 & - \\
\hline $\begin{array}{l}\text { (32) O modo como você se sente sobre a autorrevela- } \\
\text { ção feita há duas semanas mudou de lá para cá? }\end{array}$ & 17 & - \\
\hline
\end{tabular}

Além disso, os resultados também indicam que o uso da autorrevelação pelos participantes foi feito em geral visando da melhora do cliente e do andamento da sessão. Quando isso foi questionado dentro de uma questão onde poderia ser marcada mais de uma opção e que foi respondida em 15 protocolos
(Questão 9), em sete foi marcada a opção "De promover autoconhecimento no cliente", em quatro "De fornecer modelo ao cliente" e em quatro "Da intensidade dos meus sentimentos e emoções no momento". E, além da opção "Não estava consciente no momento" não ter sido marcada, das quatro descrições 
da opção "Outros", três foram categorizadas como "Promoção do vínculo terapêutico". Um exemplo dessa categoria foi "Trabalhar a interação terapeuta-cliente no aqui-agora". Da mesma forma, as descrições das autorrevelações feitas também sugeriam um uso pertinente ao contexto da sessão. Este é um dado importante, pois apesar das potenciais vantagens das autorrevelações, a literatura recomenda que sejam utilizadas de forma estratégica e consciente em relação às consequências que pode evocar (Tsai, Plummer, Kanter, Newring, \& Kohlenberg, 2010).

Ainda foi possível observar que nos quatro protocolos onde os participantes marcaram a opção "De fornecer modelo ao cliente", as descrições das autorrevelações foram categorizadas como "autorrevelações sobre experiências similares às do cliente". E que, nos casos em que as conceituações de caso foram categorizadas como "Poderia se beneficiar mais com a autorrevelação", os terapeutas participantes fizeram mais autorrevelações que nos casos categorizados como "Poderia se beneficiar menos com a autorrevelação". Assim, enquanto na primeira categoria houve uma média de 2,17 autorrevelações por participante, na segunda a média foi de 0,75.

Em seis dos sete protocolos onde as respostas dos participantes à Questão 11 foram categorizadas como "Sentiram algum desconforto em fazer a autorrevelação" durante a sessão, por exemplo "Durante a sessão me senti um pouco insegura", passaram, na Questão 12, que se referiu a como eles se sentiram após a sessão, a ter respostas categorizadas como "Sentiram-se bem em fazer a autorrevelação". Por exemplo "Após a sessão me senti mais tranquila e consegui avaliar melhor o resultado da autorrevelação", assim como em dois dos três protocolos onde as respostas da questão 11 foram categorizadas como "Tiveram sentimentos ambíguos", como "Confortável, embora o grau de exposição seja um fator que provoque estranhamento". Estas mudanças podem ser observadas na Figura 1. É relevante ainda que, apesar dessas mudanças, os participantes não relataram mudanças sobre como se sentiram com o uso da autorrevelação após duas semanas, de acordo com as respostas da Questão 32 "O modo como você se sente sobre a autorrevelação feita há duas semanas mudou de lá para cá?”.

Notou-se ainda que essas mudanças se deram nos protocolos onde o impacto no cliente foi relatado como "O cliente reagiu bem e foi relevante para o processo terapêutico", por exemplo "A cliente expressou que estava mais segura da minha vontade de atende-la", ou "O cliente reagiu bem, mas foi pouco relevante para o processo terapêutico", como "Ela entendeu minha reação no momento do encontro", o que sugere que a reação do cliente pode ter um papel importante no nível de conforto do terapeuta ao fazer uma autorrevelação. Esta hipótese ainda é corroborada pelos resultados do estudo de

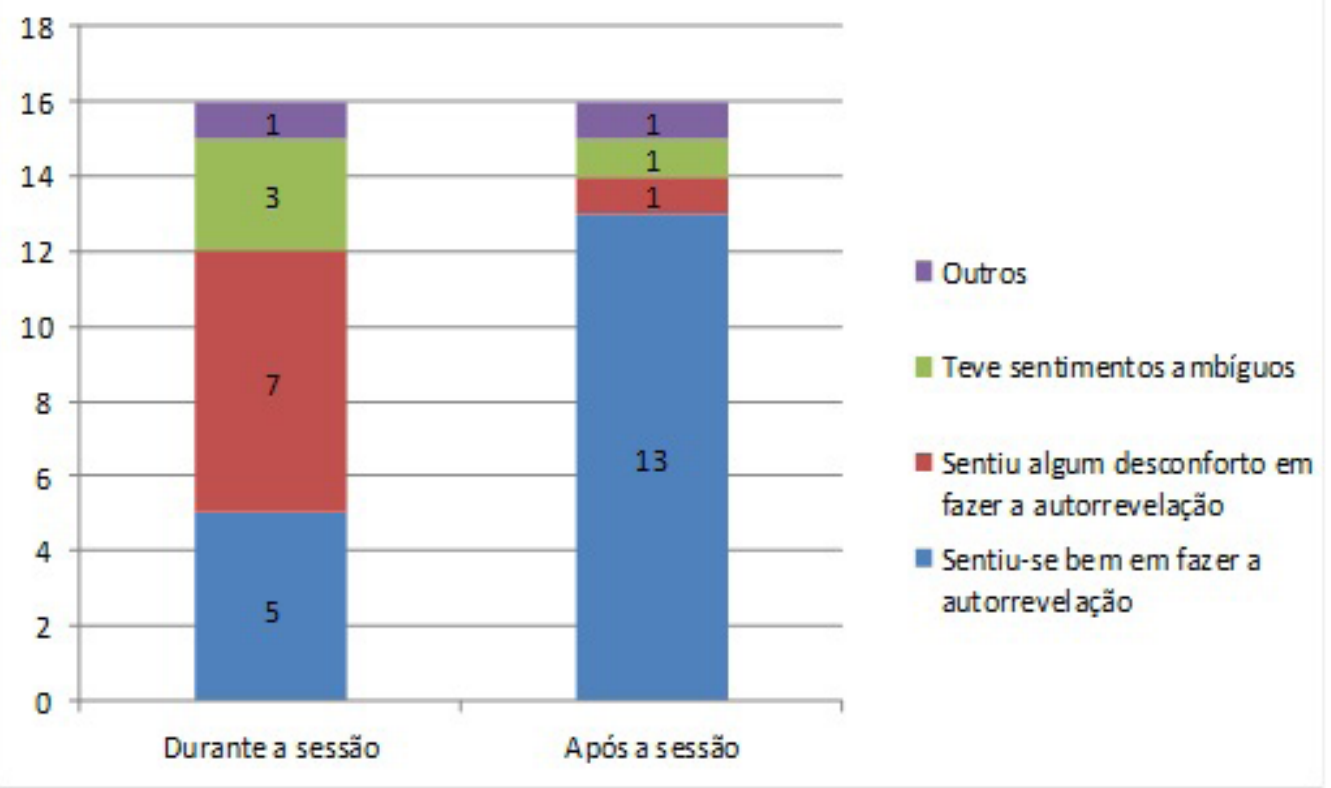

Figura 1. Como o terapeuta relatou sentir-se durante e após a sessão em que uma autorrevelação foi feita. 
Sprecher, Treger, Wondra, Hilaire e Wallpe (2013), que sugerem que a reciprocidade de autorrevelações promove uma simpatia maior que situações em que a autorrevelação é unilateral, assim, esses resultados ajudariam a explicar também a mudança positiva do relato dos terapeutas participantes sobre como se sentiam durante e após a sessão, uma vez que após a sessão a reciprocidade ou não reciprocidade do cliente já havia ocorrido.

De maneira geral, os terapeutas participantes que fizeram autorrevelações pareceram experienciar esse uso de maneira positiva. Isto pôde ser observado nas respostas de várias questões, por exemplo: em $81,25 \%$ dos protocolos onde foi relatada uma autorrevelação eles sentiram-se bem após a sessão em que foi feita a autorrevelação (Questão 12); em $87,5 \%$ sentiram-se bem com o impacto da autorrevelação no cliente (Questão 16); em 68\% repetiriam a autorrevelação com o cliente (Questão 13 "Em sessões subsequentes com esse cliente, você gostaria de repetir a autorrevelação?”); em 81,25\% consideraram que a autorrevelação valeu a pena (Questão 19 "Você considera que esta autorrevelação valeu a pena?"); e em todos os participantes declararam estar a vontade para relatar a autorrevelação ao supervisor (Questão 20 "Você está à vontade para relatá-la para o seu supervisor?”). O último dado é interessante considerando-se que, Tsai et al (2011a) recomendam que os supervisores proporcionem um ambiente onde os supervisionandos se sintam seguros e cuidados enquanto aprendem a usar a FAP. Além disso, esses resultados também estão em consonância com o estudo de Sprecher, Treger, Wondra, Hilaire e Wallpe (2013), uma vez as porcentagens relacionadas à experiência positiva do terapeuta são próximas à porcentagem de clientes que reagiram bem à autorrevelação $(87,5 \%)$ (Questão 15).

Porém, um caso em particular chamou a atenção, pois o único protocolo onde, mesmo após a sessão o terapeuta "Sentiu algum desconforto em fazer a autorrevelação" (Questão 12), também foi o único onde o terapeuta relatou que, ao repetir a autorrevelação, "Faria outros tipos de autorrevelações" (Questão 14 "Descreva-a(s) hipoteticamente"), que o impacto no cliente "Causou desconforto e foi pouco relevante para o processo terapêutico" (Questão 15), que "Sentiu algum desconforto com o impacto que a autorrevelação teve no cliente" (Questão 16) e que "Notou que ficou mais alerta às próprias autorrevelações” (Questão 23” Qual?” [o impacto no comportamento do terapeuta]) duas semanas após a autorrevelação ter sido feita. Também foi um dos seis protocolos em que o terapeuta relatou que não houve influência da autorrevelação na relação terapêutica (Questão 26 "Houve impacto na relação terapêutica ao longo destas duas semanas?"), e um dos três em que o terapeuta relatou que considerou que a autorrevelação não valeu a pena (Questão 19). Estes dados, além de corroborarem a hipótese anterior de que a reação do cliente tem influência sobre o nível de conforto do terapeuta sobre a autorrevelação, também sugerem que esse nível de conforto influencia o comportamento do terapeuta em sessões posteriores.

Quanto as possíveis influências do uso da autorrevelação sobre o cliente, notou-se que os terapeutas consideraram que os clientes tiveram, em geral, reações positivas aos usos de autorrevelações, pois $87,5 \%$ relataram que seus clientes reagiram bem de forma geral e 62,5\% reagiram bem $e$ a autorrevelação foi relevante para o processo terapêutico. A distribuição de categorias pode ser observada na Figura 2.

Porém, apesar de ter sido relatado que houve desconforto em $12,5 \%$ dos protocolos preenchidos, em 6,25\% (50\% desses 12,5\%) a autorrevelação ainda assim foi relevante para o processo terapêutico, por exemplo "Entrar em contato com sentimentos que até então estava se esquivando pelo sofrimento que traziam" (Questão 15), o que corrobora a citação de Silveira e Vandenberghe (2012), de que incidentes como desentendimentos e erros cometidos pelo terapeuta podem ajudar a evocar comportamentos-problema do cliente que costumam demorar a aparecer dentro do contexto terapêutico. Além disso, em 11 dos protocolos os terapeutas participantes relataram que houve impacto no comportamento do cliente após duas semanas (Questão 24 "Houve impacto no comportamento do cliente ao longo destas duas semanas?"), e desses, em 8 foi que "O paciente passou a ser mais aberto na relação terapêutica", como na descrição "Maior confiança para expressar insatisfações" (Questão 25 "Qual?" [o impacto no comportamento do cliente]), o que conversa com um dos dados do estudo de Guenzen 


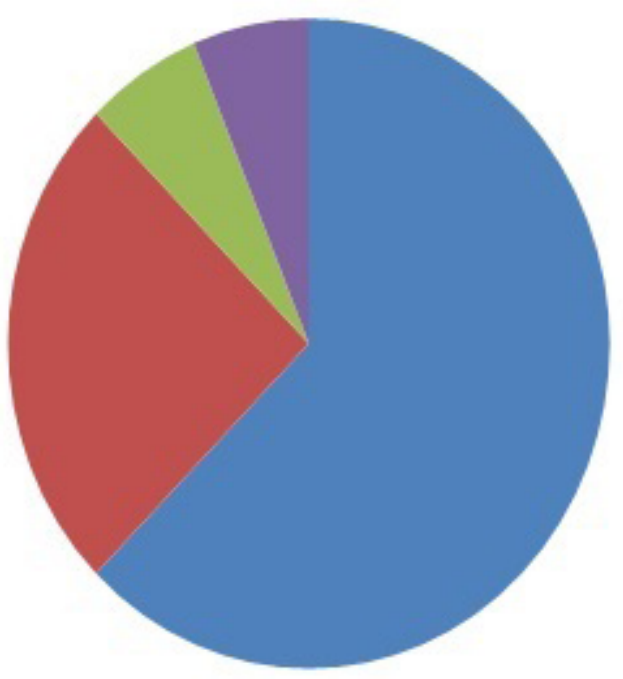

Figura 2. Relato do impacto da Autorrevelação no cliente.

(2014), de que muitas das verbalizações do cliente após a autorrevelação do terapeuta foram autorrevelações também, e sugere que essa abertura pode ocorrer tanto a curto quanto longo prazo.

Já sobre a relação terapêutica, em $62,5 \%$ das respostas, os participantes indicaram que houve influência da autorrevelação na relação terapêutica logo após a sessão (Questão 17 "Houve alguma influência da autorrevelação na relação terapêutica?"). E, desses, todas as descrições foram categorizadas como "A relação terapêutica foi fortalecida” (Questão 18 "Descreva:"[a influência]). Porém, após duas semanas, em apenas $47,05 \%$ foi relatado algum impacto na relação terapêutica (Questão 26 ), sendo que $85,71 \%$ dos que disseram que houve impacto relataram que "A relação terapêutica ficou mais forte" (Questão 27 "Qual?”[o impacto]). Dessa forma, além de os dados estarem de acordo com a afirmação de Knott, Wetterneck, Derr e Tolentino (2015) e de Tsai, Yard e Kohlenberg (2014) sobre a autorrevelação e a intimidade ajudarem a fortalecer a relação terapêutica, eles também sugerem que essa pode ser a principal mudança que as autorrevelações geram na relação terapêutica, e que essa ocorre principalmente logo após a autorrevelação ser feita.

Em relação ao desenvolvimento do caso clínico, em $58,82 \%$ das respostas os participantes relataram que houve impacto positivo no progres- so do tratamento após duas semanas (Questão 28 "Houve algum impacto positivo no progresso do tratamento após estas duas semanas?"). E, em $80 \%$ desses $58,82 \%$, as descrições foram categorizadas como "Progressos no tratamento por parte do cliente", como "A cliente se organizou de uma forma que ainda não havia feito", e os outros $20 \%$ como "Progressos na relação terapêutica", como "A relação ficou mais sincera" (Questão 29 "Qual?" [o impacto positivo]). Dessa forma, apesar de os dados não sugerirem uma grande influência do uso da autorrevelação sobre o progresso do tratamento, este parece se dar principalmente por meio de progressos do cliente.

Como o estudo foi realizado com uma amostra que se encontrava dentro de um contexto específico, sendo alunos que cursavam uma disciplina do curso de Psicologia de uma universidade específica, e sob supervisão de professoras de determinada linha teórica, os resultados apresentados podem não refletir a realidade de toda a população de alunos/terapeutas em formação, e nem mesmo de terapeutas iniciantes.

Além disso, a natureza e especificidade de cada caso e tratamento também podem ter influenciado os dados, principalmente por se tratar de uma amostra pequena de terapeutas, e na qual esses tinham pouca experiência clínica. Assim, a replicação deste estudo em outros contextos poderá gerar resultados distintos. 


\section{Conclusão}

O estudo se destinou a investigar o uso da autorrevelação e como ele é experienciado, assim como as possíveis influências sobre o cliente, a relação terapêutica e o desenvolvimento do caso clínico. Dessa forma, os resultados indicaram o uso frequente e consciente de autorrevelações pelos terapeutas participantes, a experiência, em geral, positiva do uso para aqueles que fizeram, e sua relação com a reação do cliente, que também foi boa em grande parte dos casos. Assim como o fortalecimento da relação terapêutica e, em menor porcentagem, efeitos positivos no caso clínico, após a autorrevelação ter sido feita.

Porém, um caso específico que apareceu no estudo, onde o terapeuta sentiu desconforto em fazer a autorrevelação mesmo após a sessão, alerta que o terapeuta em formação não deve ser apenas encorajado a fazer autorrevelações, mas também orientado de forma a perceber os melhores momentos de fazê-las, uma vez que como este caso sugeriu, a reação do cliente tem influência sobre como o terapeuta experiencia o uso da autorrevelação.

Outro dado desse estudo a se considerar é que, ao mesmo tempo em que a maior parte dos usos de autorrevelação foi experienciado positivamente, este uso não ocorreu na maior parte das sessões, o que também poderia indicar que os terapeutas participantes tinham um repertório adequado para distinguir as situações onde uma autorrevelação não seria apropriada.

Ainda assim, a especificidade da amostra limita a generalização dos dados para outros contextos, como terapeutas mais experientes, que tenham a sua prática baseada em outra abordagem teórica ou em pesquisas que envolvam acompanhamentos mais longos. Assim, é possível que a replicação deste estudo possa levar a resultados diferentes.

Outra limitação do estudo se deu pela formulação do questionário, que gerou alguns problemas no preenchimento de algumas questões, e assim alguns dados não puderam ser utilizados. Além disso, o questionário explorou pouco os casos em que não houve autorrevelação na sessão, e assim os motivos dos terapeutas de não utilizarem a autorrevelação não foram esclarecidos. Assim, estudos posteriores poderiam explorar melhor este tema.
Estudos futuros podem também verificar o potencial relativo da autorrevelação a depender do tipo de problema clínico, da fase do processo terapêutico e de características do cliente e do terapeuta. A abrangência de estudos que acompanhem também a supervisão dos casos também traria dados interessantes sobre a experiência dos terapeutas ao usar a autorrevelação

\section{Referências}

Banaco, R. A. (1993). O impacto do atendimento sobre a pessoa do terapeuta. Temas em Psicologia, 2,71-79. Sociedade Brasileira de Psicologia.

Braga, G. L. B., \& Vandenberghe, L. (2006). Abrangência e função da relação terapêutica na terapia comportamental. Estud. psicol. 23(3), 307-314.

Callaghan, G. M., Follette, W. C., Ruckstuhl Jr, L. E., \& Linnerooth, P. J. (2008). The Functional Analytic Psychotherapy Rating Scale (FAPRS): A Behavioral Psychotherapy Coding System. The Behavior Analyst Today, 9(1), 98.

Guenzen, L. (2014). Os possíveis efeitos do comportamento de autorrevelação do terapeuta analítico-comportamental em um processo terapêutico. Dissertação defendida na Universidade Federal do Paraná. Curitiba, Paraná.

Kameyama, M. (2012). Intervenções sobre comportamentos de clientes que produzem sentimentos negativos no terapeuta. Dissertação defendida na Universidade de São Paulo. São Paulo, São Paulo.

Knott, L. E., Wetterneck, C. T., Derr, D., \& Tolentino, R. (2015). A functional analytic perspective of therapist intimacy in and out of session. International Journal of Behavioral Consultation and Therapy, 9(4), 6-10.

Kohlenberg, R. J., \& Tsai, M. (2001). Psicoterapia analítica funcional: criando relações terapêuticas e curativas (RR Kerbauy, Trad). Santo André: ESETec, Editores Associados.(trabalho original publicado em 1991).

Manduchi, K., \& Schoendorff, B. (2012). First steps in FAP: Experiences of beginning Functional Analytic Psychotherapy therapist with an obsessive-compulsive personality disorder client. 
International Journal of Behavioral Consultation and Therapy, 7(2-3), 72.

Oliveira, J. A., \& Vandenberghe, L. (2009). Upsetting experiences for the therapist in-session: How the can be dealt with and they are good for. Journal of Psychoterapy Integration, 19(3), 231-245.

Silva, M. C. A. (2012). Metáfora: Revisão de estudos brasileiros e verificação dos prováveis efeitos em um processo de terapia analítico-comportamental. Dissertação defendida na Universidade Federal do Paraná. Curitiba, Paraná.

Silveira, J. M., \& Guenzen, L. C. (2013). Intimidade na relação terapêutica: Uma caracterização da palavra por terapeutas analítico-comportamentais [I]. Psicol. Argum, 31(74), 547-559.

Sprecher, S., Treger, S., Wondra, J. D., Hilaire, N., \& Wallpe, K. (2013). Taking turns: Reciprocal self-disclosure promotes liking in initial interactions. Journal of Experimental Social Psychology, 49(5), 860-866. doi:10.1016/j.jesp.2013.03.017

Timulak, L. (2014). Witnessing clients' emotional transformation: An emotion-focused therapist's experience of providing therapy. Journal of Clinical Psychology. 70(8), 741-752.

Tsai, M., Callaghan, G. M., Kohlenberg, R. J., Follette, W. C., \& Darrow, S. M. (2011a). Supervisão e desenvolvimento pessoal do terapeuta. In M. Tsai, R. J. Kohlenberg, J. W. Kanter, B. Kohlenberg, W. C. Follette, \& G. M. Callaghan (Orgs). Um guia para a Psicoterapia Analítica Funcional: consciência, coragem, amor e behaviorismo (pp. 211 - 247). Santo André: ESETEC Editores Associados.

Tsai, M., Kohlenberg, R.J., Kanter, J. W., Kohlenberg, B., Follette, W. C., \& Callaghan, G. M. (Orgs) (2011b). Um guia para a Psicoterapia Analítica Funcional: consciência, coragem, amor e behaviorismo (pp. 211 - 247). Santo André: ESETEC Editores Associados.

Tsai, M., Plummer, M., Kanter, J., Newring, R., \& Kohlenberg, R. (2010). Therapist grief and functional analytic psychotherapy: Strategic self-disclosure of personal loss. Journal of Contemporary Psychotherapy, 40, 1-10. doi:10.1007/s10879-009-9116-6

Tsai, M., Yard, S., \& Kohlenberg, R. J. (2014). Functional Analytic Psychotherapy: A beha- vioral relational approach to treatment. Psychotherapy. Advance online publication. http://dx.doi.org/10.1037/a0036506.

Vandenberghe, L., \& Silveira, J. M. (2012). The trouble with the short-term therapist-client relationship and what can be done about it. International Journal of Behavioral Consultation and Therapy, 7(2-3), 159.

Weeks, C. E., Kanter, J. W., Bonow, J. T., Landes, S. J., \& Busch, A. M. (2011). Translating the theoretical into practical: A logical framework of functional analytic psychotherapy interactions for research, training and clinical purposes. Behavior modification.

Wielenska, R. C., \& Oshiro, C. K. B. (2012). FAP group supervision: Reporting educational experiences at the University of São Paulo, Brazil. International Journal of Behavioral Consultation and Therapy, 7(2-3), 177.

\section{Informações do Artigo}

Histórico do artigo:

Submetido em: 25/04/2016

Primeira decisão editorial: 08/07/2016

Aceito em: 10/08/2016

Editor Associado: Jan Leonardi 